\title{
Liver Lymphangioma
}

National Cancer Institute

\section{Source}

National Cancer Institute. Liver Lymphangioma. NCI Thesaurus. Code C96841.

A rare lymphangioma that arises from the liver. It usually occurs in children and adolescents. 